\title{
Competencia y Mercado Mayorista de Electricidad: la función de monitoreo a cargo del coordinador eléctrico peruano $\left.(\text { COES) })^{(*)}\right)^{(*)}$
}

\author{
Competition and Wholesale Electricity Market: the monitoring task assigned \\ to the Peruvian electricity coordinator (COES)
}

\author{
Erick Vargas Guevara(**) \\ Quiñones Alayza Abogados (Lima, Perú)
}

Resumen: El objetivo del presente trabajo consiste en estudiar las implicancias jurídicas de la función de monitoreo del mercado mayorista eléctrico que la Ley 28832 y sus reglamentos han asignado al Comité de Operación Económica del Sistema Eléctrico Interconectado Nacional del Perú (COES). Así, se analiza la importancia de la vigilancia de la competencia en un sector estratégico y vital para cualquier país como el eléctrico y el rol del COES como colaborador del Estado peruano. Por su parte, se describen los indicadores que normalmente son utilizados para medir el nivel de competencia en el mercado eléctrico y los que aprobó OSINERGMIN el 2017.

\begin{abstract}
Asimismo, y ante el silencio al respecto de las exposiciones de motivos y de los informes de sustento de la normativa, se responde a por qué la función de monitoreo debe recaer en el COES, concluyéndose que ello se encuentra justificado por su cercanía a los agentes a los que monitorea. Justamente, esta relación permanente entre el COES y los agentes eléctricos permite al coordinador acceder a importante información de primera mano para la evaluación de los indicadores de competencia; facilidad que no tiene ninguna entidad estatal.
\end{abstract}

Palabras clave: Derecho de la Energía - Mercado de electricidad - Spot - Monitoreo Competencia - Coordinador del sistema eléctrico - COES

\begin{abstract}
The aim of this work consists in studying the legal aspects of the monitoring task on the wholesale electricity market that Law 28832 and its regulations have assigned to the Economic Operation Committee of the National Interconnected Electric System of Peru (COES). Thus, we analyze the relevance of the competition surveillance in such a strategic and vital sector for every country as the electric is and the COES' role as Peruvian government collaborator. Moreover, we describe the indicators usually used to measure the competition level within the electricity market and the ones approved by OSINERGMIN in 2017.

Likewise, and considering the silence to this respect of the legislation's statements of reasons and support reports, we answer why the monitoring function must fall to COES, concluding that it is justified in its closeness to the monitored agents. Precisely, this constant relationship between COES and electric agents allows the coordinator to access to relevant first-hand information for the competition indicators evaluation; ease that no governmental entity has.
\end{abstract}

(*) Nota del Editor: este artículo fue recibido el 30 de agosto del 2020 y su publicación fue aprobada el 26 de octubre de 2020.

${ }^{* *}$ Las opiniones expresadas son atribuibles únicamente al autor y no vinculan a las instituciones a las que este pertenece.

$\left(^{* * *}\right.$ Abogado por la Pontificia Universidad Católica del Perú (PUCP). Predocente (jefe de práctica) de "Introducción a las ciencias jurídicas" en la Facultad de Derecho de la PUCP, donde también es adjunto de docencia del área de Derecho administrativo. Capacitado en Mercados Mayoristas Eléctricos por la Organización Latinoamericana de Energía (OLADE). Asociado de Quiñones Alayza Abogados. ORCID: https://orcid.org/0000-0002-6722-7651. Correo electrónico: evargasg@pucp.edu.pe 
Competencia y Mercado Mayorista de Electricidad: la función de monitoreo a cargo del coordinador eléctrico peruano (COES)

Competition and Wholesale Electricity Market: the monitoring task assigned to the Peruvian electricity coordinator (COES)

Keywords: Energy Law - Electricity Market - Spot - monitoring Competition - Electricity system coordinator - COES

\section{Introducción}

Para que un país sea próspero, debe tener electricidad. Piénsese, por ejemplo, en las telecomunicaciones, industria alimenticia, teletrabajo o tareas del hogar; ninguna de estas actividades sería posible sin suministro eléctrico. Así, como señaló Adetoro, la energía (que incluye a la electricidad) es un elemento vital y un requerimiento básico para una sociedad civilizada, junto con la comida, techo, vestimenta y agua. No obstante, el sector energético se diferencia de otros (como la manufactura y agricultura) por su carácter de estratégico para la economía y desarrollo nacional (2006, pp. 387-389) ${ }^{(1)}$.

Por ende, el mercado en el que la electricidad se provee debe estar configurado de tal forma que permita un suministro constante y suficiente de este bien, en consonancia con la demanda que la requiere. Una de las condiciones de todo mercado para su eficiencia es la competencia, por lo que, en el caso del mercado eléctrico, es aún más fundamental.

Ahora bien, las condiciones de competencia presentes en el mercado eléctrico peruano, así como en cualquier otro mercado, sufren variaciones y fluctuaciones. Si bien estas no suelen resultar de interés para la autoridad de competencia hasta que se presentan indicios de abuso de posición de dominio o de conformación de cárteles, en mercados donde se transan bienes tan estratégicos como la electricidad puede ser indispensable que alguien se encargue de vigilar constantemente la evolución de estas condiciones.

En el caso peruano, el legislador ha partido de esta premisa para encargar -mediante la Ley $28832^{(2)}$, el Reglamento del Mercado Mayorista de Electricidad ("RMME") ${ }^{(3)}$ y el Procedimiento de Monitoreo del Mercado Mayorista de Electricidad ("Procedimiento de Monitoreo") ${ }^{(4)}$ — esta tarea a quien está en contacto permanente con los agentes del sector: el Comité de Operación Económica del Sistema Eléctrico Interconectado Nacional ("COES"), en su calidad de coordinador del despacho eléctrico.

En ese sentido, resulta de interés para los fines de este trabajo estudiar esta función del COES y sus implicancias jurídicas respecto del Mercado Mayorista Eléctrico ("MME") y el Derecho de la competencia. Así, corresponde preguntarse cuál es la importancia de vigilar la competencia en el MME, los retos que implica considerando la naturaleza de la electricidad, los indicadores que normalmente se usan para la labor del monitoreo, los que se han aprobado en Perú y por qué esta tarea debe recaer en el COES y no en la agencia estatal especializada en la defensa de la competencia (el Instituto Nacional de Defensa de la Competencia y de la Protección de la Propiedad Intelectual, "INDECOPI").

Entonces, el objetivo principal del presente trabajo consiste en responder por qué en el MME se debe institucionalizar un régimen de vigilancia permanente, considerando que el Estado peruano solo actúa en los mercados, por regla general, previa denuncia o si decide en un caso específico actuar de oficio. Por su parte, los objetivos secundarios de esta investigación son los siguientes: (i) responder por qué esta tarea debe recaer en el COES, entidad ajena en principio a la normativa de defensa de la competencia en el Perú, y (ii) analizar la naturaleza de la función de monitoreo, describiendo los indicadores que debe el COES debe evaluar.

Al respecto, se parte del hecho que el MME es un espacio de compraventa de distintos bienes o servicios, como la energía, potencia y servicios complementarios, cuya constitución responde a los siguientes objetivos: seguridad de suministro y minimización del costo total de operación del sistema. En el Perú, el MME se divide en los mercados libre y regulado, y en ambos hay transacciones físicas y financieras. A su vez, el mercado eléctrico se divide (por el lado de la oferta) en generación, transmisión y distribución y (por el lado de la demanda) en usuarios libres y regulados. Solo en la generación hay segmentos competitivos, por lo que la aplicación de los indicadores del MME por el COES tiene por objeto principal rastrear el comportamiento de los agentes en este subsector.

Asimismo, se parte del supuesto de que la competencia perfecta en un mercado es una utopía, y que, ante ciertos casos como abusos de posición dominante y formación de

(1) Traducción propia

(2) Ley para asegurar el desarrollo eficiente de la generación eléctrica, publicada el 23 de julio de 2006.

(3) Aprobado por Decreto Supremo 026-2016-EM, publicado el 28 de julio de 2016.

(4) Aprobado por Resolución del Consejo Directivo de OSINERGMIN 209-2017-OS-CD, publicada el 14 de octubre de 2017. 
cárteles, las normas específicas de defensa de la competencia se activan para proteger el mercado y los consumidores. En ese sentido, la vigilancia de la competencia es la función administrativa que permite al Estado saber si en un mercado se han violado estas normas de competencia, para así poder intervenir. No se ha establecido en ningún sector un régimen de monitoreo permanente, salvo en el caso del MME.

Finalmente, partimos de la constatación de que garantizar la competencia en los mercados eléctricos es una actividad que presenta dificultades por la propia naturaleza de la electricidad, en la medida que, por ejemplo, la generación se enfrenta a restricciones en horas punta y el almacenamiento de la electricidad representa aún altos costos (aunque la tendencia viene cambiando con los años). En ese sentido, en la industria eléctrica los incentivos de los productores, la (in)elasticidad de la demanda y el potencial para la expansión del producto juegan un rol importante en el grado de competencia.

\section{EI MME y sus segmentos competitivos}

El MME es el espacio en el que las empresas generadoras compran y venden energía, potencia y servicios complementarios, utilizando el sistema de transmisión eléctrica como plataforma física de interconexión con clientes libres y concesionarios de distribución. Así, este mercado presenta los siguientes elementos: mercado instantáneo de energía (mercado spot), mercado de contratos, mercado de capacidad o potencia de suficiencia, mercado de servicios complementarios y servicio de transmisión eléctrica (Barría \& Cerda, 2018, p. 151).

Por otro lado, la organización de un mercado eléctrico persigue los siguientes dos objetivos: la seguridad del suministro y la minimización del costo total de operación del sistema. El primer objetivo implica el mantenimiento en tiempo real del balance entre la oferta y la demanda de energía, la programación de la operación de centrales interconectadas considerando la capacidad y congestión en las líneas de transmisión, la coordinación de los programas de mantenimiento de las unidades y la provisión de servicios complementarios (ancillary services) que garanticen la estabilidad física de la red. El segundo objetivo implica el abastecimiento de la demanda con la producción de las plantas de generación con menor costo marginal de operación (Secretaría Técnica de la Comisión de Libre Competencia de INDECOPI, 2000, p. 7).
La existencia del MME es beneficiosa para la competencia, aunque existen ciertos factores a tener en cuenta. Así, según Wise, si bien la centralización y coordinación de todas las compraventas a través de una sola entidad puede favorecer el surgimiento de un monopolio, esto solo es un riesgo si en el mercado hay poca competencia entre vendedores y compradores. En ese sentido, la expansión en el territorio de las líneas de transmisión coadyuva a disminuir las preocupaciones por el ejercicio de poder de mercado (Wise, 1996, p. 275) ${ }^{(5)}$. En todo caso, siempre que el MME sea transparente y esté coordinado por una entidad independiente, será la base de que los mercados eléctricos sean competitivos, como en el caso de los Estados Unidos. Así lo reconoce la National Renewable Energy Laboratory (2016, p. 12) ${ }^{(6)}$.

Por otro lado, en los mercados que han pasado por procesos de liberalización es usual que coexistan segmentos regulados con los no regulados. Es el caso de Estados Unidos, en el que la reestructuración del mercado eléctrico ha permitido la competencia en generación y en la comercialización en los segmentos no regulados y parcialmente regulados, brindando oportunidades para los nuevos agentes.

Como señala Greer, en el marco de este proceso de reestructuración se crearon organizaciones de distribución y transmisión que proveen solo un servicio y no compran o venden energía, sino que la distribuyen en nombre de otros agentes del mercado. Estos nuevos jugadores son los merchant generators, transmission companies ("Transcos"), ISOs ${ }^{(7)}, \mathrm{RTOs}^{(8)}$, propietarios de transmisión, empresas de distribución, electric power marketers y energy service

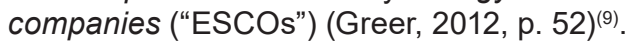

El paso de una situación de monopolio verticalmente integrado a una de estructuras de mercado donde se introduce competencia en segmentos de la industria donde ella

\footnotetext{
(5) Traducción propia.

(6) Traducción propia.

(7) Véase Independent System Operators.

(8) Véase Regional Transmission Organizations.

(9) Traducción propia.
} 
Competencia y Mercado Mayorista de Electricidad: la función de monitoreo a cargo del coordinador eléctrico peruano (COES)

Competition and Wholesale Electricity Market: the monitoring task assigned to the Peruvian electricity coordinator (COES)

es posible y deseable se da, en buena cuenta, gracias a los avances tecnológicos y a la implementación de nuevos mecanismos regulatorios. Así, en diversos países (como Inglaterra, Chile o Perú) se dieron procesos de desintegración vertical de la generación del resto de actividades eléctricas y de desintegración horizontal de las empresas de propiedad estatal para permitir el ingreso de nuevos competidores (Secretaría Técnica de la Comisión de Libre Competencia de INDECOPI, 2000, p. 7).

En Perú, la estructura y funcionamiento del MME ha sido objeto de muchos estudios en la bibliografía jurídica y económica. Sobre este tema tratan los trabajos de Quiñones (2005), Dammert, Molinelli y Carbajal (2011), Aragón (2012), Dammert, García y Molinelli (2013), Okumura (2016), Cairampoma y Villegas (2018), etcétera, a los cuales nos remitimos para estos efectos.

Al respecto, cabe mencionar que el sector eléctrico peruano se divide en dos mercados: el regulado y el libre. Dentro del primero, la formación de precios responde a mecanismos de mercado (precios firmes de licitaciones) y complementariamente a precios regulados (precios en barra). En el segundo caso, esta formación responde a precios de mercado (precios libres y precios firmes). En ambos casos, los precios de transmisión y distribución están sujetos a regulación. Asimismo, en ambos mercados hay transacciones físicas (energía y potencia) y financieras (dinero y contratos) (Dammert, Molinelli \& Carbajal, 2011, p. 127).

Ahora bien, sobre la base de la Ley de Concesiones Eléctricas $^{(10)}$, su Reglamento ${ }^{(11)}$ y la Ley 28832 , el mercado eléctrico, por el lado de la oferta, se encuentra verticalmente desintegrado en generación, transmisión, distribución y, por el lado de la demanda, en usuarios libres y regulados. Detallaremos en cada caso si se presenta un segmento competitivo(12).

- Generación: Se trata de un segmento competitivo, en el que las empresas productoras pueden instalar sus centrales de generación donde mejor les convenga y fijar precios libremente en los contratos de suministro eléctrico. Ello, sin perjuicio de que las condiciones para su participación en el MME se encuentran altamente reguladas y los precios spot son fijados por un tercero (el COES). Asimismo, los precios de potencia y energía vendidas a los distribuidores para el consumo final de los usuarios regulados están sujetos a límites (tarifas en barra o precios resultantes de las licitaciones).
- Transmisión: No es posible la competencia pues es un monopolio natural.

- Distribución: No es posible la competencia pues es un monopolio natural (al menos en Perú).

- Usuarios libres: Se trata de un segmento competitivo, pues las industrias que forman parte de él tienen libertad para negociar los precios de sus contratos de suministro eléctrico.

- Usuarios regulados: es un segmento no competitivo, pues se trata de consumidores pequeños y con poco poder de negociación, por lo que se encuentran sujetos a los precios determinados por el regulador (Organismo Supervisor de la Inversión en Energía y Minería, "OSINERGMIN").

De forma coherente con la posibilidad de competencia en generación y de los usuarios libres, la Ley $28832^{(13)}$ y el RMME ${ }^{(14)}$ han permitido que estas empresas puedan participar en el MME, bajo el siguiente esquema:

\section{Tabla 1}

\begin{tabular}{|l|l|}
\hline \multicolumn{1}{|c|}{ Rol } & \multicolumn{1}{c|}{ Participantes } \\
\hline Oferta & Generadores integrantes del COES. \\
\hline Demanda & $\begin{array}{l}\text { - Generadores. } \\
\text { - Distribuidores. Si bien es un segmento no } \\
\text { competitivo, se ha permitido su participación } \\
\text { en el MME pero solo para atender la demanda } \\
\text { de sus Usuarios Libres, mercado que sí es } \\
\text { competitivo. } \\
\text { - Grandes Usuarios (conjunto de Usuarios } \\
\text { Libres). }\end{array}$ \\
\hline
\end{tabular}

Fuente: Elaboración propia

Cabe señalar que existen diversas nuevas tecnologías que se pronostica van a impactar en los niveles de competencia de los mercados eléctricos, como nuevos tipos de plantas de energías renovables -

(10) Véase Decreto Ley 25844, publicado el 19 de noviembre de 1992.

(11) Aprobado por Decreto Supremo 009-93-EM, publicado el 25 de febrero de 1993.

(12) Ello, sin perjuicio de que la consideración de si un mercado puede ser competitivo o solo es posible el monopolio depende de una serie de factores que varían de territorio en territorio, como la tecnología disponible y el tamaño del mercado.

(13) Según su artículo 11.

(14) Según sus numerales 2.2 y 2.3 . 
energía eólica a gran altura, carreteras solares, energía solar en el espacio, energía a partir de residuos, etcétera-battery energy storage systems - almacenamiento de energía, carros eléctricos-, redes inteligentes, medidores inteligentes, microgrids, aparatos para control de energía. La integración de estas nuevas tecnologías implicará la expansión del mercado eléctrico y el surgimiento de los prosumidores, agregadores de energía, consultores de energía y comunidades energéticas como nuevos actores en el mercado (Moreno \& Gutiérrez, 2019, p. 279).

\section{Fomento y vigilancia de la competencia en el MME}

El fomento de la competencia es una cuestión fundamental en cualquier mercado. La situación ideal es que esta sea perfecta: según este modelo, las empresas (para maximizar sus beneficios) eligen el nivel de producción en el que el costo marginal es igual al ingreso marginal. Además, existe multitud de empresas pequeñas produciendo bienes idénticos y en una proporción demasiado pequeña para influir en el precio de mercado, cada una de ellas con una demanda infinitamente inelástica. El precio viene dado, de tal forma que si una empresa eleva su precio sobre el precio de mercado perderá todas sus ventas (Robles, 2001, p. 40).

En esa línea, el Libro Blanco de la Ley 28832 señala que los elementos presentes en una situación de competencia perfecta son los siguientes: "a) Muchos compradores y vendedores, que neutralicen el poder de mercado de cualesquiera de ellos; $b$ ) Capacidad de respuesta de la demanda y de la oferta a los precios; c) Mercados líquidos y eficientes d) Acceso igualitario a los servicios esenciales (de transmisión y de operación del sistema) e) Tratamiento apropiado de los aspectos que pudieran interferir con el funcionamiento del mercado" (Comisión MEMOSINERG creada por Ley 28447, 2005, p. 32).

Sin embargo, esta situación es utópica, pues lo que se dará en la mayoría de casos es un mercado con competencia imperfecta, que se produce cuando hay fallas de mercado; entre otras, cuando "existen empresas con poder de mercado, es decir, con capacidad para elevar el precio de un producto o servicio limitando su producción, dando lugar a un despilfarro que impide maximizar la eficiencia" (Robles, 2001, pp. 47-48). En el MME, así como en todos los mercados, la competencia hace posible el bienestar del consumidor, ya que mientras más competencia los precios tienden a disminuir. Por tanto, ante la presencia de fallas, se deben desarrollar los mecanismos y estrategias para su mitigación.

\subsection{Bases constitucionales y legales del Derecho de la competencia en el Perú}

El fomento y vigilancia de la libre competencia en los mercados es una tarea originaria del Estado, reconocida expresamente en la Constitución Política de 1993, cuyo artículo 61 señala que "El Estado facilita y vigila la libre competencia. Combate toda práctica que la limite y el abuso de posiciones dominantes o monopólicas (...)".

La ley que desarrolla esta misión es la Ley de Represión de Conductas Anticompetitivas ${ }^{(15)}$, aplicable a todos los mercados en general. La norma establece que el Estado, a través del INDECOPI, investiga y supervisa la libre competencia en los mercados y que puede iniciar un procedimiento administrativo sancionador ("PAS") y castigar en casos de abuso de posición de dominio y de identificarse prácticas colusorias horizontales o verticales. Para estos fines, se debe identificar previamente el mercado relevante, constituido por el mercado del producto y el mercado geográfico.

En el caso del MME, según lo que señala OSINERGMIN al responder los comentarios al Documento de Consulta DC-002-2017RIA/OS (que daría origen al Procedimiento de Monitoreo) el mercado relevante ya se encuentra definido pues se conoce a los participantes que compran y venden conforme a lo dispuesto en el RMME (2017, p. 3). Es decir, el mercado relevante sería él mismo el MME.

\subsection{Razón de ser de las normas de competencia}

El Derecho de competencia tiene su razón de ser en el respeto de los derechos de los participantes en el mercado, incluyendo los usuarios. Así, señala Montero Pascual que "las normas en materia de defensa de la competencia tienen por principal finalidad proteger la competencia en cuanto dinámica eficaz para satisfacer la demanda de los usuarios. El objeto de estas normas no es la protección de la competencia en sí, sino la protección de los intereses de los usuarios" (2013, p. 92).

(15) Decreto Legislativo 1034, publicado el 25 de junio de 2008, cuyo Texto Único Ordenado fue aprobado por el Decreto Supremo 0302019-PCM 
No obstante, estas normas no "se activan" en cualquier supuesto ni están reñidas con la formación per se de posiciones monopólicas o de dominio en un mercado; por el contrario, "la disciplina de defensa de la competencia es proclive a las situaciones de dominio del mercado cuando éstas son fruto de la eficiencia, pero, por el contrario se opone a ellas cuando éstas se generan a consecuencia de operaciones ajenas a la lógica de una mayor eficiencia y, por tanto, a los intereses de los usuarios" (Montero, 2013, p. 95).

Cuando simplemente no existe competencia en el mercado, las normas del Derecho de la competencia resultan insuficientes para garantizar su aparición — por ejemplo, en el caso de los mercados liberalizados-, por lo que entra a tallar la regulación, cuya eficacia frente a la defensa de la competencia, de aplicación expost, reside en la aplicación exante de obligaciones, que es más eficaz y garantiza una mayor seguridad a los nuevos operadores (Montero, 2013, pp. 96-99).

Con respecto a la relación entre las normas de competencia y la regulación, en el sector eléctrico prima el principio de subsidiariedad, según el cual el regulador (OSINERGMIN) solo actúa en caso el mercado y los mecanismos de libre competencia no sean adecuados para la satisfacción de los intereses de los usuarios regulados ${ }^{(16)}$.

\subsection{La vigilancia de la competencia como función administrativa}

La función administrativa es la "actividad imperativa integrada por el conjunto de tareas y cometidos administrativos (de contenido no económico o prestacional), que presuponen o implican necesariamente, en su cumplimiento, el ejercicio de autoridad, y que van desde las actividades más exclusivas y esenciales, hasta actividades de menos intensidad pero igualmente exentas de la libre iniciativa privada" (Parejo, 1992, p. 409).

Así, la actividad de vigilancia del Estado -equivalente a la supervisión, fiscalización, comprobación, inspección administrativa o monitoreo- es una de las funciones públicas del Estado (Zegarra, 2016, p. 124), cuyo objetivo principal es la verificación del cumplimiento de deberes, prohibiciones y limitaciones, por lo que se trata de un control de legalidad y no de oportunidad o eficacia. Además de ello, satisface una serie de finalidades: preventiva, cognitiva, correctiva, orientativa y auxiliar de otras potestades. En tanto potestad pública, para el ejercicio de la fiscalización se requiere de habilitación legal (Izquierdo, 2019, pp. 393-413).
Una de las manifestaciones de esta potestad es la vigilancia de las condiciones competitivas en el mercado. Así, con respecto al Derecho de la competencia, la misión del Estado "consiste en establecer las reglas del juego y vigilar su cumplimiento" (Robles, 2001, p. 35). Entonces, el Estado no interviene únicamente para garantizar la libertad, sino que, una vez asumida la tarea de dirigir la economía, tiene por objeto encauzarla hacia la consecución de ciertos objetivos predeterminados. En ese sentido, se habla, respecto de la competencia, de una función jurídica, político-social y económica (ampliación de las posibilidades de elección de los consumidores, mayores oportunidades empresariales, etcétera) (Robles, 2001, pp. 43-45).

\subsection{La especial importancia del fomento} y vigilancia de la competencia en el MME Si el fomento y vigilancia de la competencia en todos los mercados es fundamental para el bienestar de la economía y ciudadanos y para realizar el ideal de democracia en la sociedad, monitorearla en el MME constituye una tarea de la más alta prioridad, considerando la esencialidad de la electricidad. Así se ha reconocido en el segundo de los objetivos de la Política Energética Nacional del Perú 2010-2040(17), que consiste en "Contar con un abastecimiento energético competitivo". En ese sentido, en el marco de este objetivo, se establece como uno de los lineamientos de política "Establecer un marco normativo que aliente el libre acceso, la competencia y minimice la concentración del mercado, así como favorezca la transparencia en la formación de precios".

No obstante, garantizar la competencia en los mercados eléctricos es una tarea difícil por la propia naturaleza de este bien. Así lo reconoce Borenstein, para quien el problema fundamental con los mercados eléctricos es que es difícil de predecir y es casi completamente insensible a las fluctuaciones de precios ya que la generación se enfrenta a

(16) Véase Artículo 11 del Reglamento General del OSINERGMIN, aprobado por Decreto Supremo 054-2001-PCM, publicado el 9 de mayo de 2001.

(17) Aprobada por Decreto Supremo 064-2010-EM, publicado el 24 de noviembre de 2010. 
restricciones en horas punta y el almacenamiento aún es muy costoso (Borenstein, 2002, pp. 191-192)(18).

Asimismo, MacGill y Healy señalan que como la electricidad no es un bien convencional y por la complejidad de las transacciones en tiempo real, no bastan las disposiciones regulares que se establecen para la introducción de competencia en los mercados (como la desintegración vertical y horizontal). Así, los mercados eléctricos son "designer markets" ya que sus aspectos más fundamentales, incluyendo el contenido y naturaleza de los bienes transados y de los acuerdos que les sirven de base, tienen que estar definidos no solo institucional sino también tecnológicamente (MacGill \& Healy, 2013, p. 637)(19)

Así, según Borenstein, Bushnell y Knittel, en la industria eléctrica existen factores además de la concentración y de la cuota de mercado que impactan en el grado de competencia; entre otros, los siguientes:

- Los incentivos de los productores: bajo la premisa de que todo agente responderá distinto a determinado ambiente competitivo.

- La responsividad al precio (elasticidad) de la demanda: un productor que sabe que su producto es absolutamente necesario puede aprovecharse para subir sus precios a altos niveles. Ello no sucederá si la demanda es elástica.

- El potencial para la expansión del producto por los competidores y potenciales competidores: la capacidad de transmisión en una región y la capacidad de generación competitiva disponible son los factores claves para determinar el potencial para la entrada de competencia en el corto plazo o para la expansión del producto (Borenstein, Bushnell \& Knittel, 1999, p. 68)(20).

Por su parte, Vives resalta dos factores que hacen al sector eléctrico susceptible al poder de mercado: (i) la oferta es relativamente inelástica, puesto que la electricidad no es almacenable - excepto en las presas hidráulicas y en el caso de los battery energy storage system-y que existen restricciones de capacidad de oferta en el corto plazo y (ii) la demanda a corto plazo es inelástica puesto que los consumidores, particularmente los domésticos, se enfrentan típicamente a un precio regulado con independencia de su consumo.

Estas condiciones implican un poder de mercado elevado cuando la demanda y la oferta total están cerca, normalmente, en periodos de demanda alta. A su vez, el ejercicio de poder de mercado se puede dar en el nivel del sistema agregado o localmente -esto último, cuando las restricciones de transmisión crean mercados geográficos aislados-. Otro factor a considerar es la incertidumbre sobre las unidades de producción disponibles y la interacción entre tecnologías de generación múltiples con capacidad de marcar el precio en el mercado al contado (Vives, 2006, pp. 227-228).

Asimismo, señala Valdés que en el mercado eléctrico las posibilidades de afectar la operación del sistema son múltiples y tienen que ver con la información entregada por los generadores respecto al costo y/o disponibilidad de combustible, disponibilidad de las centrales, necesidades de mantenimiento, reportes de fallas, declaraciones de mínimo técnico y cualquier otro aspecto que pueda, en los hechos, afectar el despacho de las centrales, lo que altera las señales de precio, y por ende, las condiciones de competencia en el mercado (Valdés, 2018, p. 106).

En el Documento de Consulta DC-0022017-RIA/OS, OSINERGMIN señaló que el poder de mercado en el mercado eléctrico es casi siempre caracterizado por la retención - física o económica- de capacidad en el mercado. Así, en los momentos donde la demanda es cercana a la capacidad del sistema y la respuesta de demanda es débil, pequeñas variaciones en las capacidades pueden afectar el precio, y en esos momentos es difícil distinguir la distinción de capacidad y genuina falta de capacidad (2017, p. 10).

Esta retención es también documentada por Hunt, quien señala que para que sea provechosa para el agente, deben darse ciertas condiciones, como que haya barreras a la entrada de competidores al mercado y el agente retenedor tenga suficientes unidades de generación para que la ganancia obtenida por la subida del precio de la electricidad despachada por otras unidades sea mayor que las pérdidas por la capacidad disminuida (Hunt, 2002, p. 90)(21). Así, los incentivos de los generadores para ejercer su poder de mercado dependerán de su posición en el balance mensual de entregas y retiros del

(18) Traducción propia.

(19) Traducción propia.

(20) Traducción propia.

(21) Traducción propia. 
sistema. Según Borenstein, si un productor vende más de lo que compra, tendrá más incentivos para restringir su producción y así aumentar el precio spot. Pero si ha vendido gran parte de su producción bajo contratos de suministro, tendría muchos menos incentivos para incurrir en esta conducta (Borenstein, 2002, p. 202)(22).

Hunt ensaya algunos métodos para controlar el poder de mercado en la estructura del mercado eléctrico, bajo la premisa de que la mejor solución es reducir la necesidad de vigilancia (a) en primer lugar, facilitando la entrada al mercado para tener suficientes competidores, junto con una demanda responsiva a precios, (b) como segunda mejor solución, teniendo una buena cobertura de contratos (especialmente durante la transición a mercados competitivos), para que así la menor cantidad de energía sea transada en el mercado spot y (c) como último recurso, aplicando formas de regulación parcial tales como precios tope, restricciones de licitación y control de ganancias. En cualquier caso, el monitoreo será siempre necesario (Hunt, 2002, p. 105) ${ }^{(23)}$. Otros autores relacionan la posibilidad de una eficaz competencia en el MME con el régimen de la transmisión (Pierce, 1998, p. 272)(24).

En el Perú, cuando se creó por la Ley $28447^{(25)}$ la Comisión para Asegurar el Desarrollo Eficiente de la Generación Eléctrica para que plantee reformas a la normativa del sector eléctrico, se estableció como uno de sus objetivos el de asegurar el desarrollo eficiente de la generación eléctrica mediante "(i) incorporación de mecanismos de mercado" y "(iv) competencia por el mercado"(26). En ese marco, según el Libro Blanco que produjo la Comisión, uno de los objetivos del proyecto de ley propuesto, que daría paso a la Ley 28832, consistió en "Corregir, en la Ley de Concesiones Eléctricas, las deficiencias que se identificaron como barreras para el desarrollo de la competencia en el mercado de generación, e incorporar las medidas necesarias para fomentar dicha competencia" (Comisión MEM-OSINERG creada por Ley 28447 , 2005, p. 5).

Por ello, en este documento se proponen medidas orientadas hacia el impulso de la competencia en generación, para evitar el ejercicio del poder de mercado. Para ello, según el Libro Blanco, se requería "fomentar el ingreso de nuevos generadores, expandir el área geográfica del mercado liberando las restricciones de transmisión, garantizar condiciones apropiadas de salida a las plantas que resulten antieconómicas, e incorporar una institución independiente que se encargue de la operación del sistema y del mercado de corto plazo.
Adicionalmente, es esencial que la demanda pueda responder a las variaciones de los precios y que exista suficiente cobertura contractual (de largo plazo), de tal modo que la cantidad de energía transada en el mercado de corto plazo, a precios spot, sea relativamente menor" (Comisión MEMOSINERG creada por Ley 28447,2005 , p. 6).

La Ley 28832 recogió las propuestas de esta Comisión, al establecer en su artículo 2 que una de sus finalidades consiste en "c) Adoptar las medidas necesarias para propiciar la efectiva competencia en el mercado de generación; (...)".

Cabe señalar que si bien se reconoce que la introducción de mayor competencia en generación redunda posiblemente en tarifas más eficientes, también deben darse mecanismos que aseguren el abastecimiento y las inversiones en capacidad (Sánchez, 2014, p. 113). Así, la introducción de competencia en el sector eléctrico no basta para garantizar el libre acceso al mercado de nuevos agentes, por los mismos incentivos de los productores para maximizar sus beneficios (Adetoro, 2006 , p. 397)(27). Al respecto, según Hunt, entre los principales métodos para asegurar la presencia de suficientes competidores, tenemos los siguientes: (i) fomentar la entrada, (ii) expandir el área geográfica aminorando las restricciones de transmisión, (iii) dividir empresas de servicios públicos en partes para su venta a nuevas entidades, etcétera (Hunt, 2002, p. 96) ${ }^{(28)}$.

Entonces, por las características de la electricidad y del MME hacen imperativo que las condiciones de competencia, necesarias para garantizar el suministro eléctrico a la población, sean vigiladas de forma continua para evitar el ejercicio abusivo de poder de mercado por parte de los agentes. En caso contrario, estos tendrán muchos incentivos para llevar a cabo conductas de retención o disminución de su propia ofertan, con

(22) Traducción propia.

(23) Traducción propia.

(24) Traducción propia.

(25) Véase Ley que modifica el Decreto Ley 25844, publicada el 30 de diciembre de 2004.

(26) Véase Primera Disposición Final.

(27) Traducción propia.

(28) Traducción propia. 
la consecuente alza de los precios, en detrimento del consumidor.

\subsection{Casos de libre competencia en el MME peruano} La relación más cercana que existe entre libre competencia y el MME peruano se ha dado a través del control de concentraciones ${ }^{(29)}$, al tener el Perú una regulación sectorial sobre la materia ${ }^{(30)}$. Además de estos casos, tal vez el caso de libre competencia más relevante fue aquel en el que Termoselva S.R.L. denunció a diversas empresas generadoras ${ }^{(31)}$ y al COES por haber supuestamente actuado a través de los órganos de esta última para incurrir en prácticas colusorias en las modalidades de fijación concertada de precios y boicot horizontal.

En primera instancia la Comisión de Defensa de la Libre Competencia de INDECOPI ("CLC"), mediante Resolución 030-2004-INDECOPI/CLC, declararía improcedente la denuncia ya que los hechos imputados al COES habrían importado el ejercicio de potestades administrativas, lo cual no era competencia de la CLC. En segunda instancia, el Tribunal de Defensa de la Competencia y de la Propiedad Intelectual de INDECOPI, mediante Resolución 0752-2005/TDC-INDECOPI, declaró la nulidad de la Resolución 030-2004-INDECOPI/CLC y dispuso que la CLC continúe con la tramitación de la denuncia de Termoselva y emita pronunciamiento de fondo.

No obstante, posteriormente Termoselva se desistió de las pretensiones y del procedimiento a que dieron lugar su denuncia, lo cual fue aceptado por la CLC, mediante Resolución 051-2007-INDECOPI/CLC, ya que consideró que las normas bajo las cuales se dieron los actos y conductas denunciadas ya habían sido modificadas, por lo que ya había una regulación destinada a evitar que estos hechos volviesen a ocurrir.

En otros casos, el INDECOPI investigó conductas supuestamente anticompetitivas en el sector eléctrico pero decidió no iniciar un PAS. Así, mediante Resolución 006-2012/ST-CLC-INDECOPI, la Secretaría Técnica de la CLC expuso los resultados de sus investigaciones sobre una presunta práctica colusoria horizontal entre distintas empresas ${ }^{(32)}$ participantes en la Licitación Pública Internacional para el Suministro de Energía de Nuevas Centrales Hidroeléctricas para el Servicio Público de Electricidad, conducida por la entidad pública PROINVERSIÓN ${ }^{(33)}$. Finalmente, decidió no abrir un PAS pues consideró que no existían indicios razonables de colusión.

En otro caso, la Secretaría Técnica decidió, mediante la Resolución 030-2013/ ST-CLC-INDECOPI, no iniciar un PAS contra todas las empresas de generación eléctrica que participaron en los procesos de licitación de energía y potencia realizados entre 2006 y 2012 según lo dispuesto por la Ley 28832, por presuntas prácticas colusorias horizontales, al no haberse identificado indicios razonables de estas. Asimismo, recomendó al OSINERGMIN implementar una base de datos sistematizada de cada una de las próximas convocatorias de los procesos licitatorios.

Últimamente, la Secretaría Técnica de la CLC ha iniciado PAS contra distribuidoras por abuso de posición de dominio. Así, por ejemplo, inició un procedimiento contra la Empresa Regional de Servicio Público de Electricidad del Norte S.A. (distribuidora monopolística en las regiones de Lambayeque

(29) Destacan, entre otras, las Resoluciones 012-99-INDECOPI/CLC (solicitudes de adquisición de Enersis S.A. por parte de la Empresa Nacional de Electricidad S.A. de España y de Empresa Nacional de Electricidad S.A. de Chile por Enersis S.A., presentadas por Eléctrica Cabo Blanco S.A., Generandes Perú S.A., Generalima S.A. e Inversiones Distrilima S.A.), 081-2006-INDECOPI/CLC (solicitud de autorización previa de Interconexión Eléctrica S.A. E.S.P. para la adquisición de Consorcio Transmantaro S.A.), 0582009/CLC-INDECOPI (solicitud de autorización previa de Enel S.P.A. para adquirir Endesa S.A. y, a través de esta, Edegel S.A.A., Empresa Eléctrica de Piura S.A. y Edelnor S.A.A.), 030-2001-CLC/INDECOPI (solicitud de autorización previa de Tractebel S.A. para adquirir la Empresa de Electricidad de Los Andes S.A.) y la 0623-2014/SDC-INDECOPI (vinculada a la solicitud de Interconexión Eléctrica S.A. E.S.P. de revocación de condiciones impuestas a las empresas del Grupo ISA).

(30) Véase Ley 26876, Ley Antimonopolio y Antioligopolio del Sector Eléctrico, y sus Reglamentos, aprobados por el Decreto Supremo 017-98-ITINCI y el Decreto Supremo 087-2002-EF. Estas normas quedarán derogadas por el Decreto de Urgencia 013-2019, publicado el 19 de noviembre de 2019, que estableció el control de concentraciones para todos los mercados en general.

(31) Duke Energy International Egenor S. en C. por A., Empresa Eléctrica de Piura S.A., Empresa de Generación Termoeléctrica Ventanilla S.A., Edegel S.A.A., Electroperú S.A., Energía del Sur S.A., Empresa de Generación Eléctrica San Gabán S.A.

(32) Electricidad Andina S.A., Empresa de Generación Eléctrica Cheves S.A., Consorcio: Compañía Energética del Centro S.A.C. Constructora OAS LTDA., Kallpa Generación S.A., Consorcio: Empresa Eléctrica Río Doble S.A. - ABR Ingenieros S.A.C, Aruntani S.A.C., Consorcio Marañón, Empresa de Generación Huallaga S.A. y Consorcio Egecusco.

(33) Agencia de Promoción de la Inversión Privada. 
Competencia y Mercado Mayorista de Electricidad: la función de monitoreo a cargo del coordinador eléctrico peruano (COES)

Competition and Wholesale Electricity Market: the monitoring task assigned to the Peruvian electricity coordinator (COES)

y Cajamarca) ${ }^{(34)}$ y la Sociedad Eléctrica del Sur Oeste S.A. (distribuidora monopolística en la región de Arequipa) ${ }^{(35)}$ porque habrían aplicado condiciones desiguales en el mercado de comercialización de suministro de energía eléctrica a usuarios que decidían pasar de la condición de regulados a libres, vulnerando la normativa aplicable a los usuarios libres.

\section{La función de monitoreo delegada al COES}

El Documento de Consulta DC 002-2017-RIA/OS señala que la finalidad de los sistemas de monitoreo de mercado es supervisar el comportamiento de los agentes y detectar, de ser el caso, conductas anticompetitivas o fallas en el diseño del mercado que las incentiven:

Los Sistemas de Monitoreo de Mercado surgen con el objetivo de supervisar el comportamiento de los agentes y detectar conductas anticompetitivas o fallas en el diseño del mercado que incentiven a conductas anticompetitivas, las cuales pudiesen estar llevando a un desempeño ineficiente del mercado y/o afectando negativamente la operación técnica y económica, todo esto para luego proponer medidas correctivas a dichas falencias.

Un adecuado mecanismo de seguimiento del mercado, permite mejorar la competencia, aumentar la transparencia sobre los acontecimientos del mercado y mejorar el acceso a información de calidad. Las autoridades regulatorias, los participantes del mercado, y en definitiva los consumidores se beneficiarán de la información abierta sobre el estado del mercado y de las explicaciones de los acontecimientos inusuales (2017, pp. 5-8).

Ya desde el 2006, la Ley 28832 había establecido como función de interés público del COES, en su calidad de coordinador del despacho eléctrico en Perú, la de "d) Asegurar condiciones de competencia en el Mercado de Corto Plazo"(36). Este rol fue posteriormente desarrollado por el $\mathrm{RMME}^{(37)}$, que interpretó que este incluye la función de monitorear el MME:

Artículo 11.- Monitoreo del MME

11.1 El COES efectuará la función de monitoreo del desempeño del mercado de acuerdo con el procedimiento que elabore y apruebe OSINERGMIN, para asegurar condiciones de competencia de acuerdo con lo señalado en el artículo 13 de la Ley. El COES comunicará a OSINERGMIN e INDECOPI los hallazgos encontrados y de ser necesario las acciones correctivas recomendadas.

11.2 El monitoreo del mercado se realiza considerando:

a) La definición de indicadores de evaluación de condiciones de competencia del mercado.

b) El análisis del comportamiento del mercado y de sus Participantes,

c) Otros que establezca OSINERGMIN.

11.3 EI COES deberá disponer de un sistema de información que permita recolectar, administrar y procesar todos los datos requeridos para las funciones de monitoreo del MME, así como poner a disposición de los Participantes, a través de su portal de internet, toda la información correspondiente, para lo cual implementará el Procedimiento respectivo.

En esa línea, la Segunda Disposición Complementaria Transitoria del Decreto Supremo que aprobó el RMME estableció la obligación del COES de implementar "un sistema de información para la administración y monitoreo del Mercado Mayorista de Electricidad, de manera transparente y segura. Este sistema de información debe incluir los equipos, programas, portales de internet, sistemas de comunicación u otros con el fin de proveer a los agentes del mercado de información relevante sobre el Mercado Mayorista de Electricidad. El sistema de información deberá estar operativo a la entrada en vigencia del presente Reglamento".

Posteriormente, el 14 de octubre de 2017, se publicó el Procedimiento de Monitoreo, que regula a mayor detalle la función del COES

(34) Véase Nota de prensa "El Indecopi inicia procedimiento administrativo sancionador contra Ensa, empresa distribuidora de energía eléctrica en Lambayeque y Cajamarca, por un presunto abuso de posición de dominio" (2019).

(35) Véase Nota de prensa "EI INDECOPI inició un procedimiento administrativo sancionador contra SEAL, empresa distribuidora de energía eléctrica en Arequipa, por presunto abuso de posición de dominio" (2020).

(36) En el Libro Blanco de la Ley 28832 se constata una crítica a esta función: "Por otro lado, el COES no debe asumir funciones inherentes al Indecopi como las de asegurar las condiciones de competencia En todo caso, se puede señalar que el COES debe facilitar la competencia" (Comisión MEM-OSINERG creada por Ley 28447, 2005, C46).

(37) Norma que entró en vigencia el 1 de enero de 2018, conforme el Decreto Supremo 033-2017-EM. 
de supervisar las condiciones de competencia en el MME. Esta norma establece las siguientes obligaciones de cargo del COES:

- Elaborar el reporte mensual conteniendo la determinación de los indicadores de mercado (que se describirán más adelante).

- Implementar una base de datos, en la cual almacenará la información asociada a la determinación de los indicadores de mercado.

- Remitir a OSINERGMIN e INDECOPI el reporte mensual, dentro de los quince (15) primeros días del mes siguiente al de evaluación y publicarlo en su portal de internet.

- Realizar auditorías sobre los indicadores cada dos años y remitir a OSINERGMIN e INDECOPI en un informe ${ }^{(38)}$.

Según el Documento de Consulta DC-002-2017-RIA/OS, estas actividades de monitoreo tienen tres tipos de productos: (i) monitoreo permanente, donde se prueba, evalúa, mide y se reporta la performance de la industria sobre diferentes benchmarks, (ii) análisis de indicadores, donde el COES deberá incluir la relación de causas o eventos que justifiquen desviaciones atípicas de los indicadores y (iii) auditorías, que son exámenes exhaustivos donde se estudiará casos particulares que surgen esporádicamente o a pedido de OSINERGMIN (2017, p. 28).

Asimismo, en el mismo Documento se señala que el monitoreo del COES es de tipo prospectivo, "dirigido a detectar posibles fallos o vacíos que actual o potencialmente estén configurando anomalías en el mercado mayorista de electricidad, con la finalidad de desarrollar medidas correctivas hacia el futuro. Su enfoque es preventivo y dirigido al cumplimiento de objetivos regulatorios. De igual forma, para fines indicativos y de información se establecerán algunos parámetros que constituirán umbrales en vista de realizar una investigación mayor en el mercado mayorista. La ventaja de la fijación de bandas de tolerancia a los indicadores relevantes, permite identificar violaciones o incumplimiento mensual a dichos límites establecidos, situación que alerta sobre una posible anomalía en los pronósticos de COES o algún otro agente que lo realice en el que recaiga esa responsabilidad" (2017, p. 13). En el mismo sentido se pronuncia el Informe 5102017-GRT, de sustento para la aprobación del Procedimiento de Monitoreo (2017, p. 6).

Dependiendo, según el Documento, del resultado del monitoreo, se define un curso acción. Si el análisis no detecta la existencia de condiciones anormales, el proceso de monitoreo continúa efectuándose. En caso contrario, existen ciertas medidas que pueden ser tomadas, cuyo grado de efectividad depende del momento en que ello sucede (después de cuánto tiempo de detectado el problema) y del grado de intervención o peso que tengan en la operación (de corto y largo plazo). Así, algunas de estas medidas implican amonestaciones a los agentes involucrados en conductas anticompetitivas, mientras que otras pueden consistir en la intervención o modificación de una oferta, e inclusive la aplicación de una sanción punitiva (2017, p. 10).

Finalmente cabe señalar que el Procedimiento de Monitoreo, según el Informe 510-2017-GRT, no tiene por finalidad monitorear de forma específica el grado de integración de las actividades de generación, transmisión y distribución eléctrica, que según la normativa aplicable se trataría de una verificación exante a cargo de INDECOPI, sino un monitoreo expost del mercado de generación (2017, p. 5).

\subsection{Los indicadores de mercado que el COES debe analizar}

Para medir el poder de mercado en un sector se utilizan indicadores económicos, los cuales varían dependiendo del caso. Así, con respecto al sector eléctrico, según Borenstein, Bushnell \& Knittel, la medida fundamental del ejercicio de poder de mercado es el margen precio-costo, que evalúa el grado en el que los precios exceden los costos marginales. Los precios que estén por encima de estos costos pueden conllevar asignaciones ineficientes el consumo será muy bajo en respuesta a los altos precios - y transferencias inequitativas del consumidor al productor. No obstante, los costos son usualmente información privada de los productores, por lo que en la mayoría de industrias los analistas no pueden utilizar este indicador. Por ello, normalmente se utilizan medidas de concentración, como el índice Herfindahl-Hirschman Index ("HHI"), para tener un primer vistazo de la potencialidad de que surja poder de mercado (Borenstein, Bushnell \& Knittel, 1999, p. 66) ${ }^{(39)}$.

Señala Vives que la cuota de mercado y el índice de concentración $\mathrm{HHI}$ son los indicadores

(38) Véase Artículo 4.

(39) Traducción propia.

(40) Federal Energy Regulatory Commission. 
Competencia y Mercado Mayorista de Electricidad: la función de monitoreo a cargo del coordinador eléctrico peruano (COES)

Competition and Wholesale Electricity Market: the monitoring task assigned to the Peruvian electricity coordinator (COES)

utilizados habitualmente en el MME. Pero ¿respecto a qué se aplican los indicadores? Según el autor, el mercado puede ser la producción, incluyendo o no las reservas, la capacidad a corto plazo o la capacidad a largo plazo. Además, la electricidad en distintos periodos representa distintos mercados (por ejemplo, en día de demanda alta y en fase peak u off-peak) y las restricciones de transmisión pueden delimitar el mercado geográfico relevante. Una vez delimitado el mercado relevante se plantea cuál es la cuota a partir de la cual el poder de mercado puede ser problemático (la FERC ${ }^{(40)}$ de los Estados Unidos ha considerado el $20 \%$ como umbral crítico).

No obstante, alerta Vives que hay casos en los que empresas con una cuota menor pueden ejercer poder de mercado de forma sustancial, como en lo que sucedió en la crisis de California, pues cuando la demanda y la oferta son muy inelásticas, un productor que es necesario para servir a la demanda ("pivote") puede tener una gran capacidad de influenciar los precios. Entonces, se puede calcular el porcentaje del tiempo en que una empresa es pivote, para lo cual un indicador es el índice de oferta residual, que mide para una empresa la capacidad en el mercado una vez se ha sustraído la capacidad de la empresa considerada en relación a la demanda total (Vives, 2006, pp. 227-228).

Así, el Procedimiento de Monitoreo recoge algunos de los indicadores usados comúnmente, permitiendo evaluar de manera cuantitativa el desempeño del MME, sobre la base de la siguiente clasificación:

\subsubsection{Indicadores estructurales}

(a) Cuota de mercado, (b) índice HHI, (c) índice de oferta pivotal e (d) índice de oferta residual. Según el Documento de Consulta DC-002-2017-RIA/OS, sobre el análisis de la competitividad del MME, "es necesario evaluar su estructura, esto se asocia con la idea de que, en mercados con alta concentración, es más factible el ejercicio de poder de mercado, por lo tanto, este un problema estrechamente relacionado con la estructura del mercado" (2017, pp. 13-14). Al respecto, se considera como capacidad disponible a las potencias efectivas de las empresas de generación. Asimismo, la cuota de mercado se analizará por empresas de generación y no por central o grupo económico(41).

Son ejemplos de cómo el COES mide la cuota de mercado y el HHI los siguientes:

\subsubsection{Indicadores de comportamiento}

(a) Índice de Lerner e (b) índice del margen precio-costo (markup). Según el Documento de Consulta DC-002-2017-RIA/
OS, estos indicadores evalúan los aspectos conductuales de algunos agentes del mercado buscando examinar el comportamiento real de las empresas productoras, lo que implica un análisis de los precios y cantidades, con el fin de determinar si existe presencia real de poder de mercado ${ }^{(42)}$

Son ejemplos de cómo el COES mide estos indicadores los siguientes:

\subsubsection{Indicador de la red de transmisión:} Índice de monitoreo de la red de transmisión. En el Documento de Consulta DC-0022017-RIA/OS, OSINRGMIN señala que a través de la manipulación de la congestión puede lograrse que generadores con una localización específica ganen poder de mercado (2017, p. 23).

Este mismo Documento señala que estos indicadores fueron elaborados y definidos sobre la base de los criterios de "(A) Relevancia - cómo el indicador evalúa la medida de interés; (B) Credibilidad - calidad de los datos para el cálculo; y (C) Practicidad - costo y facilidad de cálculo" (2017, p. 5).

Conforme al artículo 7 del Procedimiento de Monitoreo, el COES deberá incluir la relación, de manera discriminada, de causas o eventos que justifiquen desviaciones atípicas de estos indicadores, así como una breve descripción y su respectiva cuantificación. Asimismo, es obligación de OSINERGMIN establecer valores referenciales para cada indicador, sobre la base de la información de como mínimo 12 meses transcurridos ${ }^{(43)}$, obtenida a partir de la base de datos histórica para cada indicador ${ }^{(44)}$.

Por otro lado, según el artículo 8.1 del Procedimiento de Monitoreo, los límites o bandas de tolerancia que establecerá OSINERGMIN tienen como objetivo fijar estándares que permitan alertar sobre posibles comportamientos anómalos de las variables monitoreadas. Así, conforme el numeral 8.2, que entrará en vigencia cuando OSINERGMIN apruebe los valores

(41) Véase Respuesta al Documento de Consulta DC-002-2017-RIA/OS de OSINERGMIN (2017), 6.

(42) Véase 2017, 17.

(43) Véase Única Disposición Complementaria Final.

(44) Véase Artículo 8.2. 
Figura 1

Cuota de mercado por cada empresa durante junio 2020.

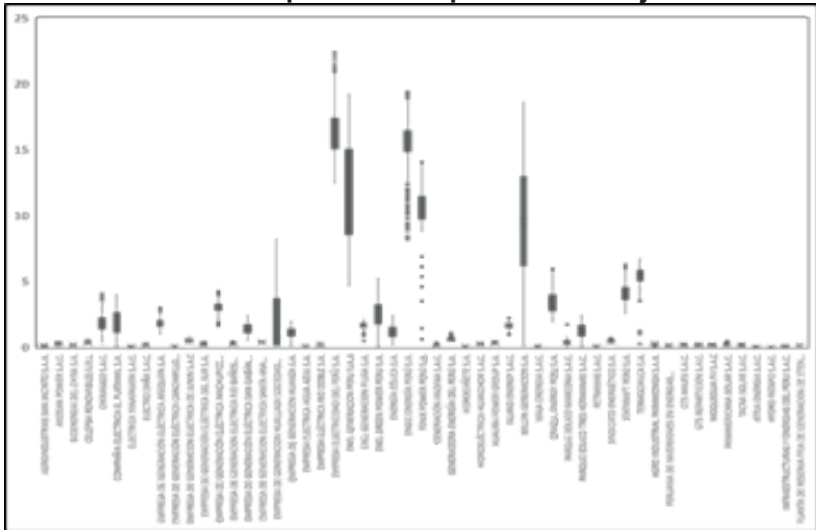

Fuente: Informe COES/D/SGI-113-2020.

Figura 2

Nivel de concentración de mercado durante junio 2020 según el índice HHI.

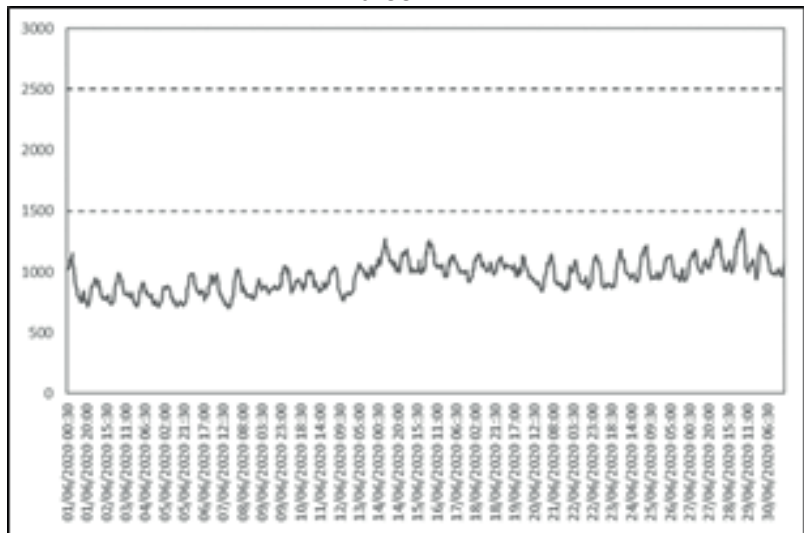

Fuente: Informe COES/D/SGI-113-2020.

señalados, el error (\%) será la diferencia entre el valor del indicador real del MME y el valor de referencia establecido por OSINERGMIN para un período - mes, semana o día, según sea el caso-, conforme a la fórmula establecida en el Procedimiento.

En virtud de la función que le ha sido encomendada, COES ha venido cumpliendo periódicamente con emitir (a) un reporte mensual de indicadores para el monitoreo del MME, desde enero de 2018, y (b), por medio de su Sub Dirección de Gestión de la Información, un reporte mensual sobre revisión de las desviaciones atípicas en el MME, desde abril de 2020. Esta información es colgada en el portal web del COES, sin perjuicio de su obligación de remitirla al INDECOPI y OSINERGMIN.

\subsection{La técnica de delegación empleada: el COES como colaborador del Estado}

Según la Ley 28832, el COES es una entidad privada con personería de Derecho público (art. 12.2) ${ }^{(45)}$. En ese marco, mediante la atribución legal al COES de la función de asegurar condiciones de competencia en el MME, se convierte éste en un colaborador del Estado, que es el que en realidad tiene la competencia originaria para vigilar la competencia en la generalidad de los mercados. Al respecto, consideramos que en este caso se dio la figura del encargo de gestión, reconocida en el artículo 82.4 de la Ley del Procedimiento Administrativo General(46).

Al respecto, si bien estamos de acuerdo con Lagos en que en esta figura caben supuestos como el del COES, no compartimos su posición según la cual con esta figura no se atribuye el ejercicio de auténticas funciones públicas sino meras actividades materiales que no implican decisión (Lagos, 2017, p. 278). Ello, en la medida que con esta figura se pueden atribuir potestades de fiscalización, cuyo carácter de ser actividades materiales no se contradice con su naturaleza de ser verdaderas funciones públicas, conforme lo ya analizado.

Podemos señalar que esta función, junto con las demás encomendadas al COES, tienen su origen y contexto en que el MME es un mercado altamente técnico y de una complejidad tal que desborda la capacidad organizativa, técnica y cognoscitiva de la Administración pública. Es justamente en este tipo de ámbitos que cobra fuerza y relevancia

(45) No es objeto de este estudio analizar la naturaleza jurídica de esta entidad, por lo que para ello nos remitimos al trabajo de Cairampoma y Villegas (2018).

(46) Véase Ley 27444, cuyo Texto Único Ordenado fue aprobado por Decreto Supremo 004-2019-JUS, publicada el 11 de abril de 2001 : Artículo 82.- Encargo de gestión

(...) 82.4 Mediante norma con rango de ley, puede facultarse a las entidades a realizar encargos de gestión a personas jurídicas no estatales, cuando razones de índole técnico y presupuestado lo haga aconsejable bajo los mismos términos previstos en este artículo, dicho encargo deberá realizarse con sujeción al Derecho Administrativo. 
Figura 3

Valores del índice de Lerner durante junio 2020.

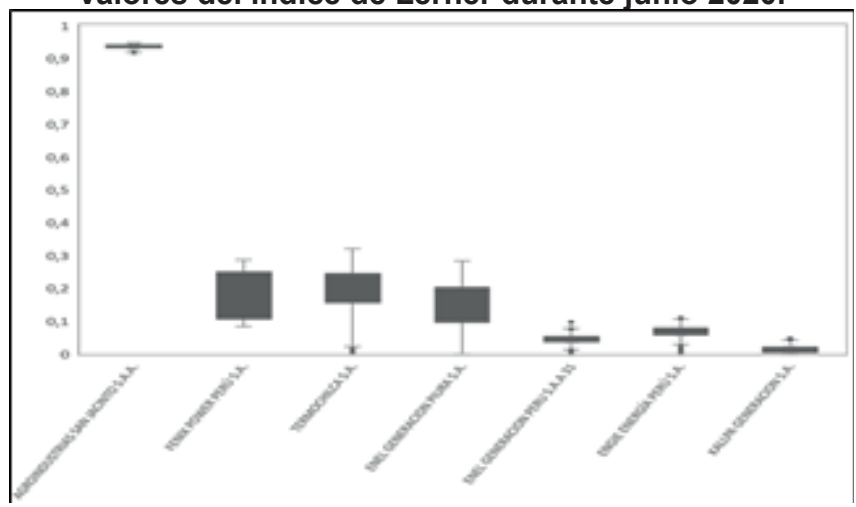

Fuente: Informe COES/D/SGI-113-2020.

Figura 4

Valores del índice Mark up durante junio 2020.

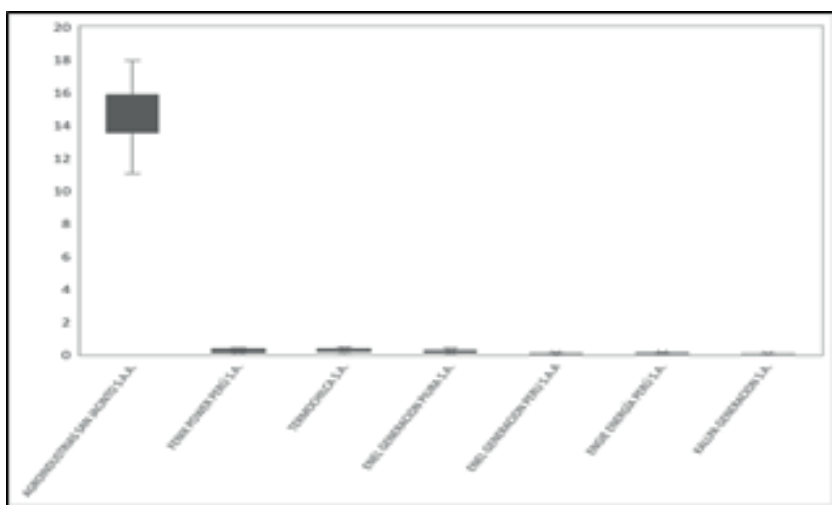

Fuente: Informe COES/D/SGI-113-2020.

la colaboración de los privados en el ejercicio de funciones públicas, tales como las acciones de supervisión, control e inspección (Zegarra, 2016, p. 127).

Así, señalan Galán y Prieto sobre este fenómeno de colaboración privada que se basa en tres razones: (a) falta de medios de la Administración, tanto materiales como personales, (b) falta de conocimientos técnicos de la Administración, como en el caso de sectores como un alto grado de complejidad técnica y (c) mejora de la calidad y eficacia en la gestión. Así, subrayan la relevancia de que los trabajadores expertos de la entidad privada tengan un nivel adecuado de formación técnica y que la organización de la entidad cuente con medios técnicos adecuados para el correcto ejercicio de la función. Asimismo, se pretende que estas entidades ejerzan sus funciones con imparcialidad y objetividad (Galán \& Prieto, 2008, p. 69, pp. 74-75).
Canals resalta que, ante el progreso y complejidad tecnológica actuales, la función pública de inspección y control adquiere connotaciones declarativas e incluso decisorias, por lo que solo el conocimiento especializado permite la constatación de determinados hechos y la tarea de subsumir el supuesto de hecho en la norma jurídica concreta, la cual, en muchos casos, remite a normas técnicas de naturaleza extrajurídica (Canals, 2011, p. 29).

Por otro lado, en estos casos es normal que no se atribuya la totalidad del ejercicio de la función pública al privado. En ese sentido, la Administración mantiene una relación estable y permanente con la entidad privada colaboradora y tiene siempre la posibilidad de ejercer directamente la función y de supervisar el cumplimiento de esta de la entidad privada (Galán \& Prieto, 2008, pp. 7879). Finalmente, el traslado del ejercicio de las funciones públicas conlleva, paralelamente, el traslado de la responsabilidad que pueda derivarse de ese ejercicio (Galán \& Prieto, 2008, p. 93).

Cabe señalar que a pesar de la diferencia entre los términos "asegurar" —usado por la Ley 28832- y "monitorear" —usado por el RMME y el Procedimiento de Monitoreo-, en nuestra opinión, la Ley 28832 ya había otorgado en el 2006 al COES la potestad implícita de monitorear el MME. Al respecto, según García de Enterría y Fernández, los poderes inherentes o implícitos pueden inferirse por interpretación de potestades expresamente reconocidas, más allá de la literalidad de las normas que las crean, tal como poderes concomitantes, filiales o derivados (García de Enterría \& Fernández, 2006, p. 486).

Entonces, aun cuando la norma con rango de ley había delegado al COES la función de "asegurar" condiciones de competencia, ello conllevaba de forma implícita la función de monitorearla, pues para lo primero es necesario lo segundo. Uno no puede asegurar algo que no conoce o no observa. Este rol del COES como colaborador del Estado queda expreso en el Informe 510-2017-GRT, en el que se señala que el Procedimiento de Monitoreo no tiene por objeto establecer sanciones de conductas infractoras $\mathrm{ni}$ 
determinar los órganos para imponerlas, reconociendo que ello se encuentra regulado por la normativa respectiva y respetando la autoridad de INDECOPI (2017, p. 5).

\section{3. ¿Por qué el COES?}

Hemos estudiado el vehículo jurídico por el cual se ha atribuido al COES la potestad de monitorear el MME. No obstante, ante el silencio de los documentos e informes que sirvieron de sustento para la elaboración de la Ley 28832, RMME y Procedimiento de Monitoreo, cabe responder por qué se ha atribuido esta función específicamente a esta entidad.

En el ámbito chileno, donde el Coordinador del mercado eléctrico tiene facultades similares a las del COES respecto del MME, se ha señalado que "esta función de monitoreo está dirigida a que el nuevo Coordinador se constituya en un verdadero colaborador de las autoridades de libre competencia, por su especial conocimiento técnico y su privilegiada posición, que le permite acceder a cuantiosa información en tiempo real, y observar situaciones sobre el funcionamiento del mercado eléctrico a las que la Fiscalía Nacional Económica y el Tribunal de Defensa de la Libre Competencia no podrían o les resultaría muy difícil y costoso acceder" (Valdés, 2018, p. 101).

En la misma línea, se considera que esta función será un aliciente o incentivo para que los actores del mercado eléctrico adecúen su comportamiento a las normas de libre competencia, ya que estarán mucho más conscientes de que serán observados permanentemente por un ente técnico. Esto resulta de vital importancia "ya que sin perjuicio del alto grado de rivalidad existente en la industria, la interacción forzada y permanente entre los distintos operadores del sector constituye un desincentivo importante a la interposición de denuncias o la presentación de demandas por parte de los afectados por prácticas que podrían ser constitutivas de infracciones a la libre competencia" (Valdés, 2018, pp. 101-102).

Entonces, consideramos que se encuentra justificado tanto técnica como jurídicamente la atribución al COES de la función de monitorear el MME. Ello, pues es la entidad que, aun sin pertenecer al Estado, se encuentra más cerca del MME y de sus actores, ya que se encarga de coordinarlos a cada instante y tiene acceso a información de primera mano, a diferencia de lo que ocurre con OSINERGMIN o INDECOPI. Resultaba natural que, si el COES se comunica permanentemente y en tiempo real con las empresas del sector, sea la encargada de vigilar sus conductas en el MME, así como sus aspectos estructurales.

\section{El monitoreo del MME en otros ordenamientos}

\subsection{Estados Unidos de Norteamérica}

La Energy Policy Act de 2005(47), modificó la Federal Power Act (16 USC 824t), empoderando a la FERC para que facilite la transparencia de precios en los mercados para la venta y transmisión de energía eléctrica en el comercio interestatal, para satisfacer el interés público, la integridad de los mercados, la libre competencia y la protección de los consumidores $^{(48)}$. Asimismo, se estableció que una comisión especial —integrada por 5 miembros, incluyendo a un representante de la FERC - se encargaría de emitir el Electric Energy Market Competition Task Force ${ }^{(49)}$, que tendría como objetivo analizar la competencia dentro de los mercados mayorista y minorista de energía eléctrica en los Estados Unidos ${ }^{(50)}$.

Por su parte, el Código de los Estados Unidos ${ }^{(51)}$ establece que es ilegal que cualquier entidad directa o indirectamente

(47) Del 8 de agosto de 2005. Véase Subtítulo G "Market Transparency, Enforcement, and Consumer Protection". Véase https://www. govinfo.gov/content/pkg/STATUTE-119/pdf/STATUTE-119-Pg594.pdf

(48) Traducción propia de "(a)(1) The Commission is directed to facilitate price transparency in markets for the sale and transmission of electric energy in interstate commerce, having due regard for the public interest, the integrity of those markets, fair competition, and the protection of consumers".

(49) Véase Título XVIII. Sección 1815 (a).

(50) "(b) STUDY AND REPORT.

(1) STUDY.The task force shall conduct a study and analysis of competition within the wholesale and retail market for electric energy in the United States".

(51) Véase Título 16 "Conservation", Capítulo 12 "Federal Regulation and Development of Power", Subcapítulo II "Regulation of Electric Utility Companies Engaged in Interstate Commerce". Sección 824v. "Prohibition of energy market manipulation".

(52) "(a) In general It shall be unlawful for any entity (including an entity described in section 824(f) of this title), directly or indirectly, to use or employ, in connection with the purchase or sale of electric energy or the purchase or sale of transmission services subject to the jurisdiction of the Commission, any manipulative or deceptive device or contrivance (as those terms are used in section 78j(b) of title 15), in contravention of such rules and regulations as the Commission may prescribe as necessary or appropriate in the public interest or for the protection of electric ratepayers".

(53) Véase Docket PL05-1-000. 27 de mayo de 2005. Véase https://www.ferc.gov/sites/default/files/2020-04/E-5_16.pdf 
Competencia y Mercado Mayorista de Electricidad: la función de monitoreo a cargo del coordinador eléctrico peruano (COES)

Competition and Wholesale Electricity Market: the monitoring task assigned to the Peruvian electricity coordinator (COES)

use, con relación a la compra o venta de energía eléctrica o de servicios de transmisión, cualquier mecanismo engañoso o manipulativo, en contravención de las regulaciones que la FERC establezca para satisfacer el interés público o para proteger a los consumidores ${ }^{(52)}$.

Así, la FERC cuenta con la colaboración de los Market Monitoring Units, asociados a los ISO y RTO. Según señala la Policy Statement on Market Monitoring Units de la FERC ${ }^{(53)}$, "MMUs perform an important role in assisting the Commission in enhancing the competitiveness of ISO/RTO markets". En ese sentido, los MMU se encargan de identificar reglas de mercado y provisiones tarifarias inefectivas, identificar potenciales conductas anticompetitivas de los participantes del mercado y proveen un análisis crítico de mercado y comprehensivo para una informada decisión de política. Según Hunt, los monitores de mercado podrían ser un brazo útil para la FERC para la revisión de cómo los mercados vienen funcionando, más que cómo deberían funcionar (2002, p. 316) ${ }^{(54)}$.

De detectarse las conductas señaladas, los MMU deben notificarlo a la FERC, sin perjuicio de sus labores de monitoreo y de emitir reportes regulares sobre la estructura del mercado eléctrico dentro del área del respectivo ISO o RTO. Asimismo, se reconoce en la Policy Statement que como los mercados eléctricos existen en última instancia para beneficiar a los consumidores, el MMU debería concentrarse en cuán eficiente es la respuesta de mercado a las necesidades de los consumidores por un suministro confiable de electricidad. Así, en casos en los que el MMU tiene razones para creer que se ha producido una violación al mercado, debe presentar un nonpublic referral a la FERC siguiendo los protocolos del Apéndice A de la Policy Statement ${ }^{(55)}$.

En el 2019 Report on enforcement, la FERC señala que recibió 16 referrals de MMUs, de los cuales 11 tuvieron que ver con potenciales manipulaciones de mercado, siete con violaciones de provisiones tarifarias y cuatro con conductas prohibidas por las reglas de la FERC sobre comportamiento en el mercado. Tres de estos referrals sirvieron de base para investigaciones abiertas en el 2019 (2019, pp. 41-43) ${ }^{(56)}$.

\subsection{Reino de España}

En este país el mercado de producción se organiza como pool con diversos mercados horarios (diarios, intradiarios y otros complementarios). El mercado central en España es el diario (day-ahead), que combina aspectos de los mercados establecidos en el Reino Unido y los países nórdicos (NordPool). En este mercado participan las empresas generadoras, distribuidoras, comercializadoras y los consumidores elegibles. La participación en el mercado es obligatoria, excluyendo a los contratos bilaterales físicos, que en la práctica se han dado muy poco por una regulación desincentivadora (Vives, 2006, p. 226).

La Ley 24/2013, de 26 de diciembre, del Sector Eléctrico(57), establece en su artículo 29 (numeral 2, literal n), que el operador del mercado tiene la función de comunicar "a la autoridad competente cualquier comportamiento de los agentes del mercado que pueda suponer una alteración del correcto funcionamiento del mismo".

\subsection{República de Chile}

Mediante Ley $20.936^{(58)}$ se modificó el Decreto con fuerza de Ley $4 / 20.018^{(59)}$, que fija texto refundido, coordinado y sistematizado de la Ley General de Servicios Eléctricos. Así, se le agregó el artículo $72^{\circ}-10$ "Monitoreo de la Competencia en el Sector Eléctrico", con el siguiente tenor: "Con el objetivo de garantizar los principios de la coordinación del sistema eléctrico, establecidos en el artículo $72^{\circ}-1$, el Coordinador monitoreará permanentemente las condiciones de competencia existentes en el mercado eléctrico. En caso de detectar indicios de actuaciones que podrían llegar a ser constitutivas de atentados contra la libre competencia, conforme las normas del Decreto con Fuerza de Ley 1, del año 2004, del Ministerio de Economía, Fomento y Reconstrucción, el Coordinador deberá ponerlas en conocimiento de la Fiscalía Nacional Económica o de las autoridades que corresponda".

Según Valdés, los principales aspectos de esta normativa son, entre otros, los siguientes: (a) se ha fortalecido y ampliado la obligación de los coordinados de proporcionar la información que el Coordinador requiera

(54) Traducción propia.

(55) "Referrals to the Commission for Enforcement".

(56) Traducción propia.

(57) Véase https://www.boe.es/buscar/pdf/2013/BOE-A-2013-13645-consolidado.pdf

(58) Establece un nuevo sistema de transmisión eléctrica y crea un organismo coordinador independiente del sistema eléctrico nacional. Ley publicada el 20 de julio de 2016. Véase https://www.leychile.cl/N?i=1092695\&f=2017-02-09\&p=

(59) Publicado el 5 de febrero de 2007. Véase https://www.leychile.cl/N?i=258171\&f=2019-12-21\&p= 
para el cumplimiento de sus funciones, reconociendo la facultad de este último para realizar auditorías, (b) se ha reforzado la capacidad del Coordinador para instruir medidas para el adecuado funcionamiento del sistema, (c) se ha instituido un deber de elaborar reportes periódicos del desempeño del sistema eléctrico, estableciendo que cada coordinado deberá poner a disposición del Coordinador todos los antecedentes necesarios para determinar el grado de desempeño de las instalaciones y (d) se han reconocido atribuciones particulares respecto de la construcción, interconexión, puesta en servicio, operación, retiro, modificación, desconexión y fallas de las instalaciones eléctricas, etcétera (Valdés, 2018, p. 103).

\section{Conclusiones}

En la medida que la industria de la electricidad es esencial y fundamental para el bienestar de la economía y ciudadanos, se justifica la existencia de un monitoreo permanente del nivel de competencia en el mercado en el que se desarrollan las actividades eléctricas. Existen otras industrias y actividades económicas importantes como la agricultura, pesquería, minería, etcétera, pero consideramos que la electricidad reviste una esencialidad tal que, sin ella, ninguna de estas actividades sería posible. Es por ello que es necesaria una vigilancia constante y periódica de los mercados eléctricos, en el entendido que una restricción a la competencia en ellos perjudicará a todos los usuarios y actividades que, en su totalidad, dependen de la electricidad.

Esta tarea debe recaer en el COES pues es la entidad que coordina todos los días del año, a todas horas, con los agentes del sector y que cuenta con el nivel de especialización técnica que le permite conocer y entender con mayor precisión las conductas de las empresas eléctricas. Asimismo, por su cercanía a estas, cuenta con una cantidad y calidad de información de primera mano que le permite cumplir esta labor con eficiencia. Así, si bien INDECOPI es la agencia estatal encargada de la defensa de la competencia, no cuenta ni con el expertise ni nivel de información necesarios como para cumplir esta tarea de vigilancia.

La actividad de monitoreo del MME no es nada más ni nada menos que una función administrativa que recae originalmente en el Estado, llamado a vigilar los niveles de competencia en los mercados, que ha sido delegada al COES, en tanto agente que está en mejor posición para cumplirla. Mediante esta delegación, el COES debe evaluar indicadores estructurales (cuota de mercado, índice $\mathrm{HHI}$, índice de oferta pivotal e índice de oferta residual), de comportamiento (índice de Lerner e índice del margen precio-costo) y de la red de transmisión, convirtiéndose así en un verdadero colaborador del Estado, pues sus reportes son enviados al INDECOPI y OSINERGMIN y pueden servir de insumo para el ejercicio de sus potestades públicas.
Estas ideas son útiles para alcanzar el objetivo principal de la investigación en tanto que la pregunta de por qué debe existir un régimen de monitoreo permanente y periódico en el MME puede ser respondida con la constatación fáctica de la existencia del COES: existe un COES, en términos generales, porque (a) los mercados eléctricos son de tal esencialidad que requieren de un tercero imparcial que coordine la oferta y demanda en tiempo real y porque (b) la naturaleza del bien transado (electricidad) requiere de este tercero que programe en qué momento exacto debe ingresar cada productor (despacho) y que calce constantemente esta oferta con la demanda. De ello, y considerando que en ciertos segmentos del MME hay libre competencia y que las características de la industria posibilitan el surgimiento de posiciones dominantes, se deriva naturalmente que sus indicadores deban ser analizados permanentemente.

\section{Referencias bibliográficas}

Adetoro, D. (2006). Can the Imposition of a Regulator in Any Liberalised Energy Market Be Justified by Market Behaviours?. Journal of Energy \& Natural Resources Law, 24(3), 384-402. https:// doi.org/10.1080/02646811.2006.11433443

Aragón, I. (2012). El mercado de electricidad en el Perú. Revista de Derecho Administrativo, (12) 2, 165-174. http://revistas.pucp.edu.pe/index.php/ derechoadministrativo/article/view/13529/14155

Barría, C. \& Cerda, M. P. (2018). Alcances del monitoreo de competencia del Coordinador Independiente del Sistema Eléctrico Nacional. Revista de Derecho Administrativo Económico de la Pontificia Universidad Católica de Chile, 26, 131161. https://doi.org/10.7764/redae.26.8

Borenstein, S. (2002). The Trouble with Electricity Markets: Understanding California's Restructuring Disaster. The Journal of Economic Perspectives, 16(1), 191-211. http://doi. org/10.1257/0895330027175

Borenstein, S., Bushnell, J. \& Knittel, C. (1999). Market Power in Electricity Markets: Beyond Concentration Measures. The Energy Journal, 20(4), 65-88. http://doi.org/10.5547/ISSN01956574-EJ-Vol20-No4-3

Cairampoma, A. \& Villegas, P. (2018). Los alcances jurídicos del Comité de Operación Económica del Sistema Interconectado Nacional del Perú. Revista 
Competencia y Mercado Mayorista de Electricidad: la función de monitoreo a cargo del coordinador eléctrico peruano (COES)

Competition and Wholesale Electricity Market: the monitoring task assigned to the Peruvian electricity coordinator (COES)

de Derecho Administrativo Económico de la Pontificia Universidad Católica de Chile, 26, 23-39. https://doi.org/10.7764/redae.26.2.

Canals, D. (2011). El ejercicio de funciones públicas por entidades privadas colaboradoras de la Administración. En A. Galán \& C. Prieto (dirs.), El ejercicio de funciones públicas por entidades privadas colaboradoras de la Administración (pp. 21-52). Huygens Editorial.

Comisión de Defensa de La Libre Competencia de INDECOPI. (2004, 19 de mayo). Resolución N 030-2004-INDECOPI/CLC, recaída en el Expediente 012-2002/CLC.

Comisión de Defensa de la Libre Competencia de INDECOPI. (2007, 14 de setiembre). Resolución $N^{\circ}$ 051-2007-INDECOPI/CLC, recaída en el Expediente 012-2002/CLC.

Comisión MEM-OSINERG (2005). Proyecto de Ley para Asegurar el Desarrollo Eficiente de la Generación Eléctrica. http://www2.osinerg. gob.pe/MarcoLegal/docrev/LEY-28832-CONCORDADO.pdf

Comité de Operación Económica del Sistema Interconectado Nacional. (2020, 14 de julio). Informe COES/D/SGI-113-2020 "Revisión de las desviaciones atípicas en el RIMME".

Dammert, A., Molinelli, F. \& Carbajal, M. (2011). Fundamentos técnicos y económicos del sector eléctrico peruano. OSINERGMIN.

Dammert, A., García, R. \& Molinelli, F. (2013). Regulación y supervisión del sector eléctrico. Fondo editorial de la Pontificia Universidad Católica del Perú.

Federal Energy Regulatory Commission (2019, 21 de noviembre). 2019 Report on enforcement. Docket No. AD07-13-013. Office of Enforcement. https://cms.ferc.gov/sites/default/files/2020-05/11-2119-enforcement.pdf

Galán, A. \& Prieto, C. (2008). El ejercicio de funciones públicas por entidades privadas colaboradoras de la Administración. Anuario de Derecho Municipal, 2, 63-104. https://repositorio.uam.es/ handle/10486/664240

García de Enterría, E. \& Fernández, T. (2006). Curso de Derecho Administrativo. T I. Versión latinoamericana, en base a la duodécima edición. Palestra Editores.

Greer, M. (2012). Electricity Marginal Cost Pricing. Applications in Eliciting Demand Responses. Butterworth-Heinemann.

Hunt, S. (2002). Making competition work in electricity. John Wily \& Sons.

Instituto Nacional de Defensa de la Competencia y de la Protección de la Propiedad Intelectual (2019, 13 de noviembre). El Indecopi inicia procedimiento administrativo sancionador contra Ensa, empresa distribuidora de energía eléctrica en Lambayeque y Cajamarca, por un presunto abuso de posición de dominio [comunicado de prensa]. https://bit.ly/3064mfo

Instituto Nacional de Defensa de la Competencia y de la Protección de la Propiedad Intelectual (2020, 6 de julio). El Indecopi inició un procedimiento administrativo sancionador contra SEAL, empresa distribuidora de energía eléctrica en Arequipa, por presunto abuso de posición de dominio [comunicado de prensa]. https://bit.ly/3jL3wMZ

Izquierdo, M. (2019). Fiscalización, supervisión e inspección administrativa: aproximación conceptual crítica y caracteres generales en el Derecho peruano. En D. Zegarra (coord.), La proyección del
Derecho Administrativo Peruano: estudios por el Centenario de la Facultad de Derecho de la PUCP (pp. 387-418). Palestra Editores.

Lagos, F. (2017). El ejercicio de funciones públicas por entidades privadas colaboradoras de la Administración [tesis para optar el título de abogado, Pontificia Universidad Católica del Perú]. Repositorio PUCP. http://tesis.pucp.edu.pe/ repositorio/handle/123456789/9476

MacGill, I. \& Healy, S. (2013). Chapter 20 - Is Electricity Industry Reform the Right Answer to the Wrong Question? Lessons from Australian Restructuring and Climate Policy. En F. Sioshansi (ed.), Evolution of Global Electricity Markets: New Paradigms, new challenges, new approaches (pp. 615-644). Academic Press. https://doi.org/10.1016/ C2012-0-00444-9.

Montero, J. (2013). Regulación económica y Derecho de la competencia. Dos instrumentos complementarios de intervención pública para los mercados de interés general. En A. Ruiz (dir.), Fundamentos de regulación y competencia (el diálogo entre Derecho y Economía para el análisis de las políticas públicas) (pp. 81-111). lustel.

Moreno, L. \& Gutiérrez, A. (2019). Novedades del derecho de la competencia y de los usuarios del servicio público de energía eléctrica como consecuencia de la incorporación de las tecnologías disruptivas en Colombia. En L. Moreno (dir.), C. Villanueva (coord.), Anuario Iberoamericano de Derecho de la Energía. Vol II: Regulación de la Transición Energética (pp. 271-287). Universidad Externado de Colombia.

National Renewable Energy Laboratory (2016). Competitive Electricity Market Regulation in the United States: A Primer. NREL. https://www.nrel. gov/docs/fy17osti/67106.pdf

Okumura, P. (2015). El Mercado Mayorista de Electricidad en el Perú. THEMIS-Revista de Derecho, 68, 261-277. http://revistas.pucp.edu.pe/ index.php/themis/article/view/15598/16047

Organismo Supervisor de la Inversión en Energía y Minería (2017). Documento de Consulta. Propuesta que establece Indicadores de Competencia en el Mercado Mayorista Eléctrico. DC-002-2017-RIA/OS

Organismo Supervisor de la Inversión en Energía y Minería. (2017). Informe $N^{\circ}$ 510-2017-GRT. Opinión legal sobre la procedencia de publicar la Norma "Procedimiento para Monitorear el Mercado Mayorista de Electricidad", y procedencia de establecer un periodo transitorio para la aplicación del PR-46, cuando entre en funcionamiento el Mercado Mayorista de Electricidad. Asesoría Legal de la Gerencia de Regulación Tarifaria de OSINERGMIN 
Organismo Supervisor de la Inversión en Energía y Minería. (2017). Respuestas de OSINERGMIN a los comentarios recibidos por el Documento de Consulta DC-002-2017-RIA/OS.

Parejo, L. (1992). Manual de Derecho Administrativo (2. ${ }^{a}$ ed). Editorial Ariel.

Pierce, R. (1998). The Antitrust Implications of Energy Restructuring. Natural Resources \& Environment, 12(4), 269-275.

Quiñones, M. (2005). Mercado eléctrico en el Perú: ¿una utopía?. THEMIS-Revista de Derecho, 50, 7385. http://revistas.pucp.edu.pe/index.php/themis/ article/view/8750/9135

Robles, A. (2001). Libre competencia y competencia desleal (examen del artículo 7 de la Ley de Defensa de la Competencia) (1. ${ }^{\mathrm{a}}$ ed). La Ley.

Sánchez, E. (2014). ¿Mayor competencia en el sector eléctrico peruano?. Revista de Economía y Derecho, 11(41), 101-124. https://revistas.upc.edu. pe/index.php/economia/article/view/308

Secretaría Técnica de la Comisión de Libre Competencia de INDECOPI. (2000). Estructura y funcionamiento del Comité de Operación Económica del Sistema Eléctrico Peruano.
Secretaría Técnica de la Comisión de Defensa de la Libre Competencia de INDECOPI. (2012, 23 de abril). Resolución Nº06-2012/ST-CLCINDECOPI, recaída en el Expediente Preliminar 014-2009/CLC.

Secretaría Técnica de la Comisión de Defensa de la Libre Competencia de INDECOPI. (2013, 11 de diciembre). Resolución N 030-2013/STCLC-INDECOPI, recaída en el Expediente Preliminar 020-2008-CLC.

Secretaría Técnica de la Comisión de Defensa de la Libre Competencia de INDECOPI. (2020). Resolución Nº05-2020/ST-CLC-INDECOPI.

Tribunal de Defensa de la Competencia y de la Propiedad Intelectual de INDECOPI. (2005, 8 de julio). Resolución N 0752-2005/TDCINDECOPI, recaída en el Expediente 012-2002/CLC.

Valdés, J. (2018). El rol del nuevo Coordinador Eléctrico Nacional en su misión de monitorear las condiciones de competencia en el mercado eléctrico. Revista de Derecho Administrativo Económico de la Pontificia Universidad Católica de Chile, (26), 95-115. https://doi. org/10.7764/redae.26.6

Vives, X. (2006). El reto de la competencia en el sector eléctrico. En J. C. Jiménez \& J. García (coor.), Energía: Del Monopolio al Mercado. CNE, diez años en perspectiva (pp. 223-246). Civitas.

Wise, M. (1996). Overview: deregulation and antitrust in the electric power industry. Antitrust Law Journal, 64(2), 267-278.

Zegarra, D. (2016). La participación de los privados en la actividad de supervisión en el sector eléctrico peruano: breve aproximación a su estudio. THEMIS-Revista de Derecho, 69, 123-131. http://revistas. pucp.edu.pe/index.php/themis/article/view/16755/17077 
